\title{
Relationship between cleaning rates and ectoparasite loads in coral reef fishes
}

\author{
Alexandra S. Grutter \\ Department of Marine Biology, James Cook University of North Queensland, Townsville, Queensland 4811, Australia
}

\begin{abstract}
Individuals from 11 fish species were followed and the number of times and duration that fish were inspected by the cleaner wrasse Labroides dimidiatus were recorded around Lizard Island, Great Barrier Reef. The frequency and duration of inspection were positively correlated with the mean parasite load and mean surface area of the 11 fish species. Surface area, however, explained slightly more of the variation in inspection frequency and duration among species than did ectoparasite load. This suggests surface area may be useful for predicting the cleaning rates of fish species. When the frequency and duration of inspection were corrected for mean surface area and mean ectoparasite load, differences among fish species disappeared. Observations of 3 size classes from 1 fish species, Hemigymnus melapterus, revealed that larger fish, which have more parasites, were inspected more often and for longer periods than smaller fish with fewer parasites. The fact that fish with more parasites are cleaned more suggests that parasites play an important role in fish cleaning interactions.
\end{abstract}

KEY WORDS: Cleaning symbiosis Ectoparasites Fish behavior - Labroides dimidiatus

\section{INTRODUCTION}

The stimuli that motivate a fish to seek cleaning are crucial to the study of cleaning behavior (Losey 1987, 1993, Poulin 1993), as is the need for new approaches to this phenomenon (Losey 1987, Poulin 1993). Studies using cleaner fish models suggest that tactile stimuli drive host cleaning (Losey \& Margules 1974, Losey 1977, 1979). The influence of ectoparasites on the response of fish toward cleaners is conflicting and remains unresolved (Losey 1971, 1979). Parasites were found to have little effect on the response of one host species towards cleaner fish models while they only increased the response to tactile stimuli in another host species (Losey 1979). An examination of the relationship between cleaning rates and parasite load is needed to understand the role of parasites in cleaning interactions.

Most studies that have measured fish cleaning rates have quantified cleaning from the perspective of the cleaner (Okuno 1969, Hobson 1971, Potts 1973). The motivation for cleaner fish to clean is food, thus this sampling method provides information on the foraging and feeding behavior of cleaner fish. However, it can create confounding problems if used to estimate the cleaning rates of hosts. Cleaner fish prefer some fish over others (Gorlick 1978, 1984) and often clean some fish in proportion to their abundance (pers. obs.).

Observations that focus on the host, rather than on the cleaner fish, measure how often individuals are cleaned. How host cleaning rates vary among species and within species can provide a measure of the relative importance or potential effect of cleaning. Host attributes that may influence cleaning behavior can also be correlated with these cleaning rates. The relationship between these characteristics and cleaning rates may be useful for predicting cleaning rates and may also provide insight into what drives cleaning rates.

The study of cleaning behavior is complicated by several factors. Fish abundance, fish size, and ectoparasite loads all vary among host species. Most importantly, cleaning rates can be influenced as much by the actions of the cleaner fish as by the actions of the host (Losey 1971). Therefore, when measuring cleaning behavior, it is difficult to completely separate the effect of the cleaner from the effect of the host. When exploring factors that may explain variation in cleaning, fac- 
tors that may influence host behavior should be considered, as well as those that may influence cleanerfish feeding. For cleaner fish, the motivation to clean is obvious; they obtain food. Cleaner fish prefer host species with more ectoparasites (Gorlick 1984) or with more mucus (Gorlick 1978). Another factor that may influence cleaner fish behavior is host size. Ectoparasite load is often correlated with host size in fish (Noble et al. 1963, Cressey \& Collette 1971, Bortone et al. 1978, Buchmann 1989, Grutter 1994). Larger fish may also represent a richer source of food for cleaners in the form of mucus and other surface materials.

For host fish, the motivation to respond to a cleaner fish may be ectoparasite removal, which can be either the proximate or ultimate cause of the behavior or both (Gorlick et al. 1978). The average ectoparasite load of some hosts has been shown to be speciesspecific (Grutter 1994). Thus different parasite loads may result in different cleaning rates among species. There is also intraspecific variation in parasite loads (Grutter 1994), which may affect responses to hosts. Despite several studies (Gorlick 1978, 1984, Losey 1979), the role of parasites in cleaning interactions, particularly in host fish cleaning behavior, is still not fully understood.

It is likely that cleaning rates result from an interaction of host size and parasite load but there is little information on the parasite loads of fish and their relationship to size and cleaning rate. The objectives of this study are divided into 2 parts. The first part was designed to: (1) test whether inspection by the cleaner fish Labroides dimidiatus was correlated with parasite load and size (surface area) of host fish species; (2) apportion variation in inspection rates due to parasite load and host size; and (3) test whether there were any true species differences in cleaning rates once inspection was adjusted for parasite load and surface area. A second general aim was to test whether inspection rates within a host species differed among 3 size classes of fish which have different parasite loads (Grutter 1994).

\section{METHODS}

The fish species (family) investigated were Ctenochaetus striatus (Acanthuridae), Scolopsis bilineatus (Nemipteridae), Siganus doliatus (Siganidae), Scarus sordidus (Scaridae), Thalassoma lunare, Hemigymnus melapterus (Labridae). Acanthochromis polyacanthus, Neopomacentrus azysron, $N$. cyanomos, Ambliglyphidodon curacao, and Pomacentrus moluccensis (Pomacentridae). The species were selected because they live in similar habitats, they differ ecologically but are all reef associated, they are relatively abundant, and are all cleaned by the cleaner wrasse Labroides dimidiatus. The body sizes of the 11 fish species investigated ranged from 33 to $250 \mathrm{~mm}$ in standard length (estimated from fish collected for parasites).

The study was carried out at several sites (North Point, Granite Bluff, Lagoon, and Casuarina Beach) around Lizard Island $\left(14^{\circ} 40^{\prime} \mathrm{S}, 145^{\circ} 26^{\prime} \mathrm{E}\right)$ on the Northern Great Barrier Reef. These sites were selected because fish at these locations were accessible for observations and for collections of parasites. The sites are shallow reefs ( 2 to $6 \mathrm{~m}$ ) that have low exposure to prevailing south-east trade winds.

Host cleaning behavior. Focal-animal sampling (Altmann 1974) was used to estimate host cleaning rates. This method records actions that are directed to or received by the observed animal and, over a fixed length of time, this record provides an estimated rate of the behavior recorded (Altmann 1974). During sampling, a host fish was selected haphazardly and observed from a distance of 2 to $5 \mathrm{~m}$. The abundance of each fish species was relatively high which reduced the likelihood that the same fish were accidentally selected more than once (pseudoreplication). Inspection time by the cleaner fish was used as a measure of cleaning behavior because it could be measured more precisely than other feeding behaviors of Labroides dimidiatus. Inspection was defined as any event that involved visual examination of the body surfaces and gills of the host. The length of an inspection event was determined from the time when a cleaner fish approached a host fish until it departed the host. The duration of inspection is positively correlated with number of bites (Youngbluth 1968, Losey 1971, pers. obs.) taken by cleaner fish and thus estimates amount of feeding. The duration of each inspection of a host by $L$. dimidiatus was recorded, and the frequency of inspections per sampling period calculated. These were summed over the 30 min sample period to obtain the total number of times a fish was inspected and the total duration of inspection received by cleaner fish. The length of each sampling period was sufficient to record at least 1 cleaning event per period for most fish species, yet sufficiently short to allow at least 2 sample periods per dive. Sample periods that had no inspections were recorded as zeros. All observations were made by a SCUBA diver so that mobile species could easily be followed and were made between 07:00 and 18:00 h

Inspection rates among species. The fish species Acanthochromis polyacanthus, Ctenochaetus striatus, Scolopsis bilineatus, Siganus doliatus, Scarus sordidus, Thalassoma lunare, and Hemigymnus melapterus were sampled at North Point during January 1993 ( $\mathrm{n}=$ 16 to 18 per species). Sampling was divided equally 
into 4 time periods $107: 00$ to $08: 59,09: 00$ to $11: 59,12: 00$ to $14: 59$, and $15: 00$ to $19: 59 \mathrm{~h}$ ) and an initial 2-factor analysis of variance (ANOVA) was used to test whether there was a time of day effect on the frequency and duration of inspection. The factor time and the interaction term (time $\times$ species) were not significant $(0.50>p>0.15)$ so both the frequency and duration of inspection for these 7 species were pooled across times.

The remaining fish species, Neopomacentrus azysron, N. cyanomos, Ambliglyphidodon curacao, and Pomacentrus moluccensis, were sampled 10 to 11 times in November 1993. These samples were taken at 8 small patch reefs in the Lagoon and near Casuarina Beach. It was assumed that the relationships between cleaning rates and parasites or surface area were not influenced by time or site (a preliminary analysis of the cleaning rates of Hemigymnus melapterus at 2 different times and at 2 sites revealed no significant effect of time or site). Based on this assumption, these observations were combined with those of the above 7 species to increase the sample size. All fish within each species were of a narrow range of adult sizes.

To test how species differed in their cleaning rates when parasite load and surface area were used as covariates an analysis of covariance (ANCOVA) was conducted. Covariates estimated as mean number of parasites per fish species and mean surface area of each species were calculated from fish collected after the observations. This meant that fish used for estimating the parasite load and surface area were not the same as those observed, thus a mean was used for each species in the analyses. To determine whether one covariate explained more of the variation in the frequency of inspections or whether both explained the variation equally, covariates were added to the ANCOVA sequentially. The analysis was then repeated with the order of the covariables reversed. This resulted in 2 models which were compared to determine whether one or both covariables best explained the variation in inspection frequency. Type 1 sums of squares, also called sequential sums of squares, were used because the effects of each factor are sequentially removed from the model (SAS 1991). Thus covariables are added one at a time and are cumulative. The same analyses were used to test for differences in the duration of inspection among species. For all the above analyses, frequency and duration of inspection were $\log _{10}(x+1)$-transformed, and parasite load and surface area were $\log _{10}$-transformed to satisfy the assumption of homogeneity of variance and linearity.

Inspection rates within Hemigymnus melapterus. In the second set of observations, inspection rates were recorded across a size range of $H$. melapterus.
This species was selected because it shows a strong correlation between ectoparasite load and host size (Grutter 1994). To determine if inspection rates varied with size of fish, 3 size classes of fish were distinguished $(<8 \mathrm{~cm}, 10$ to $15 \mathrm{~cm}$, and $>20 \mathrm{~cm}$ in standard length), and fish were selected haphazardly from these size classes. Thirty sampling sessions were done at Turtle Beach in August 1992. The duration and frequency of inspections among size classes were tested with an ANOVA. Data were $\log _{10}(x+1)$-transformed to satisfy the assumption of homogeneity of variance.

Parasite load estimates. The mean parasite load of each fish species was estimated from fish collected several days after the behavioral observations. The species Acanthochromis polyacanthus, Ctenochaetus striatus, Scolopsis bilineatus, Siganus doliatus, Scarus sordidus, Thalassoma lunare, and Hemigymnus melapterus (a combined total of 34 fish) were collected with a barrier net and handnet and placed in a plastic bag underwater. Collections were made from North Reef, Granite Bluff, and the Lagoon. The parasite loads of these fish species show very little variation among these sites (Grutter 1994), and thus, all parasite samples from fish were pooled across sites. Parasites were collected following Grutter (1994) which involved rinsing fish with saltwater, soaking the fish in the anesthetic chloretone for 30 to $60 \mathrm{~min}$, filtering all liquids at $200 \mu \mathrm{m}$, then $57 \mu \mathrm{m}$, and then scanning the whole fish under a stereo microscope $(35 \times)$ to recover any remaining parasites. The gills of $H$. melapterus, which contain many copepods, were removed, fixed in $10 \%$ formalin, and examined later for parasites. The parasite assemblage of the 7 species included copepods, isopods, monogeneans, digeneans, turbellarians, and other platyhelminths.

Using a $1.5 \times 1 \mathrm{~m}$ barrier net with $10 \mathrm{~mm}$ mesh, specimens ( $n=8$ per species) from the species Ambliglyphidodon curacao, Neopomacentrus azysron, $N$. cyanomos, and Pomacentrus moluccensis were collected in a similar way from areas of observations. The parasites of $A$. curacao were collected as above, but fish were not scanned under a microscope after the soak. Their gills were removed in an identical manner as the gills of Hemigymnus melapterus. The remaining species, $N$. azysron, $N$. cyanomos, and P. moluccensis, are relatively small ( 33 to $53.6 \mathrm{~mm}$ ) so the whole fish and contents of the plastic bag were fixed and the fish surface, gills, and fixative examined for parasites under a stereo microscope $(25 x)$. The parasites of these 4 species were mainly copepods with a few digeneans, monogeneans, and turbellarians.

Fish collected for parasite estimates were similar in size to the fish used during behavioral observations, except for Hemigymnus melapterus. Individuals of the 
size observed could not be captured in sufficient numbers. The parasite load of $H$. melapterus is positively correlated with standard length (Grutter 1994), thus its parasite load was estimated from the mean standard length observed $(23.8 \mathrm{~cm}$ ) using Grutter (1994).

Surface area estimates. Surface area is a measure of host size that is particularly useful when making comparisons among species with different morphologies. It is also an appropriate measure of host size for studies that involve ectoparasite loads and cleaner fish, which feed on mucus, skin, scales, and ectoparasites all which are found on the surfaces of fish. To estimate the surface area of an individual, an outline of the fish body and fins was drawn (Grutter 1994). The area of this drawing was measured using computer software Framegrabber 3.2 and Image 1.4. Surface area of Neopomacentrus azysron, N. cyanomos, and Pomacentrus moluccensis was measured using the fish collected for measurement of parasite loads. Specimens of the remaining 8 species were not available for surface area measurements. Therefore their areas were estimated from their standard lengths using other specimens measured as described above. The suface areas of Ambliglyphidodon curacao were measured using specimens collected as above $(n=11, r>0.95)$. The surface areas of the remaining 7 species were estimated similarly using Grutter (1994) ( $n=16$ to 26 per species, all $r>0.95$ ).

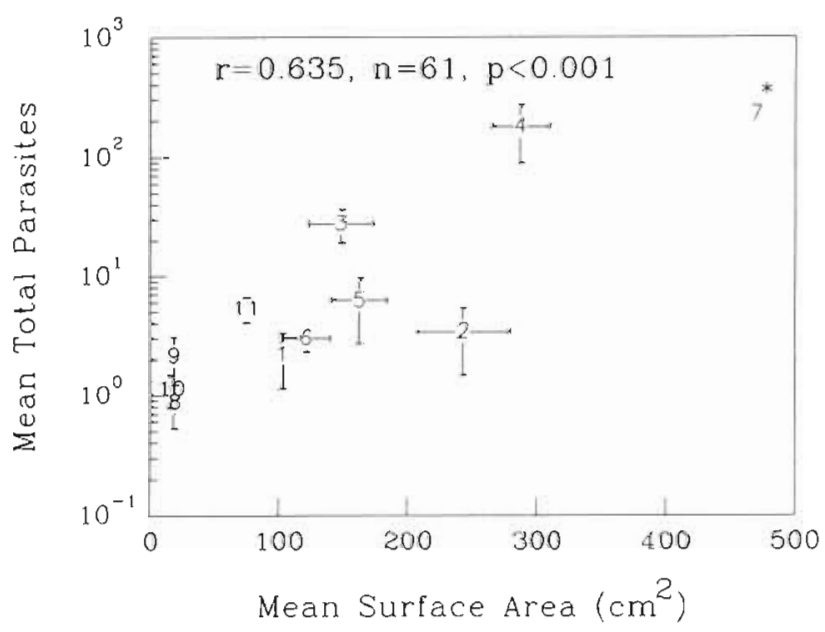

Fig. 1. The mean number of parasites $( \pm \mathrm{SE}$ ) per fish species as a function of mean surface area ( \pm SE) of the fish species. The number of parasites were $\log _{10}$-transformed to satisfy the assumption of linearity in the correlation analysis. 1: Acanthochromis polyacanthus, 2: Ctenochaetus striatus, 3: Scolopsis bilineatus, 4: Siganus doliatus, 5: Scarus sordidus, 6: Thalassoma lunare, 7: Hemigymnus melapterus, 8: Neopomacentrus azysron, 9: $\mathrm{N}$. cyanomos, 10: Pomacentrus moluccensis, 11: Ambliglyphidodon curacao. *: no SE available as parasite load was estimated from the mean standard length of fish observed

\section{RESULTS}

The mean parasite load of each species increased exponentially as the mean surface area of the fish species increased (Fig. 1). The number of times fish were inspected increased as parasite load increased (Fig. 2a) and as the surface area of the fish species increased (Fig. 2b). The species with the highest inspection rate was the large Siganus doliatus, which had about 110 parasites per fish and which was inspected about 6 times per $30 \mathrm{~min}$ (Fig. 2). This species's cleaning rate does not differ throughout the day (see 'Methods'), which means that on average, individuals of this spe-
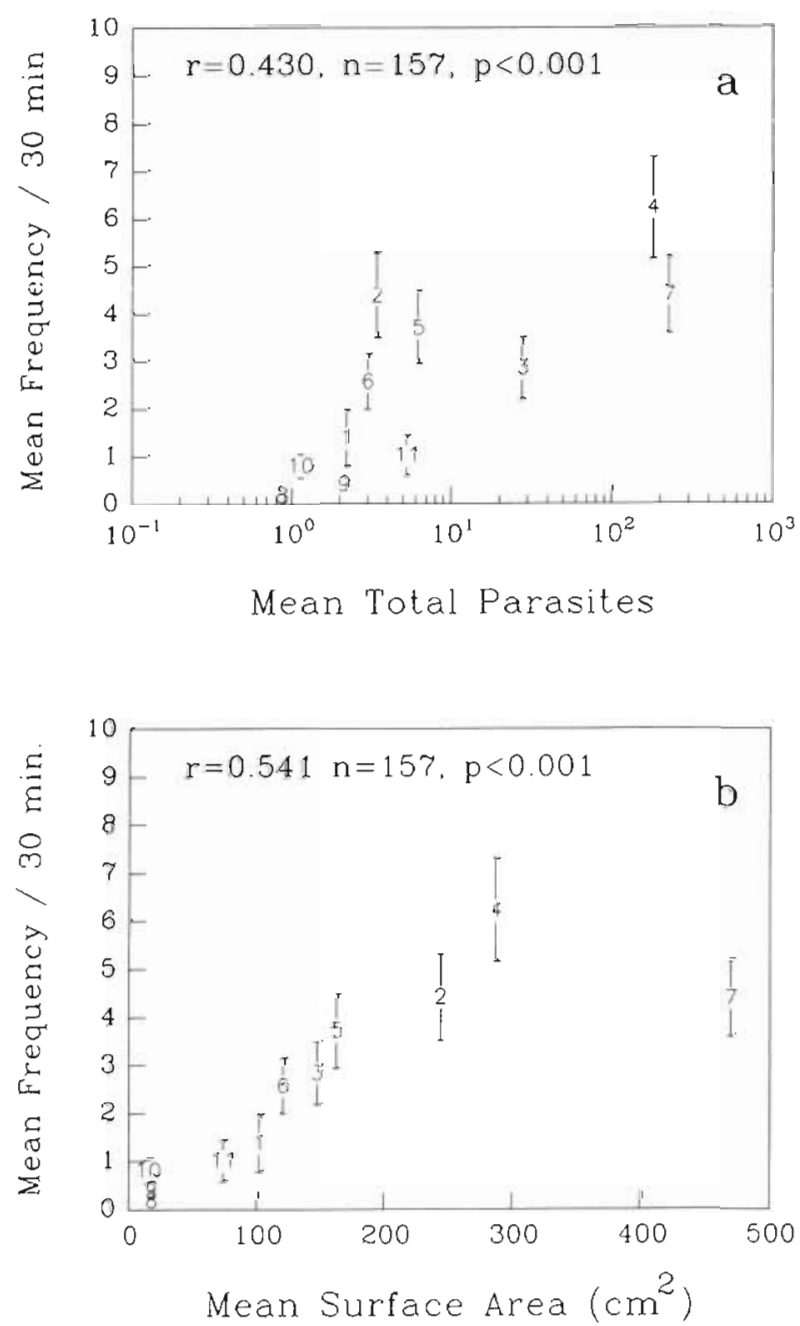

Fig. 2. The mean number of inspections ( \pm SE) by Labroides dimidiatus per 30 min observation period as a function of (a) mean number of parasites per fish species and (b) mean surface area per fish species. The frequency of inspection was $\log _{10}(x+1)$-transformed while both mean parasites and mean surface area were $\log _{10}$-transformed to obtain linearity and homogeneity of variance for the correlation analyses. See Fig. 1 for definitions of species 

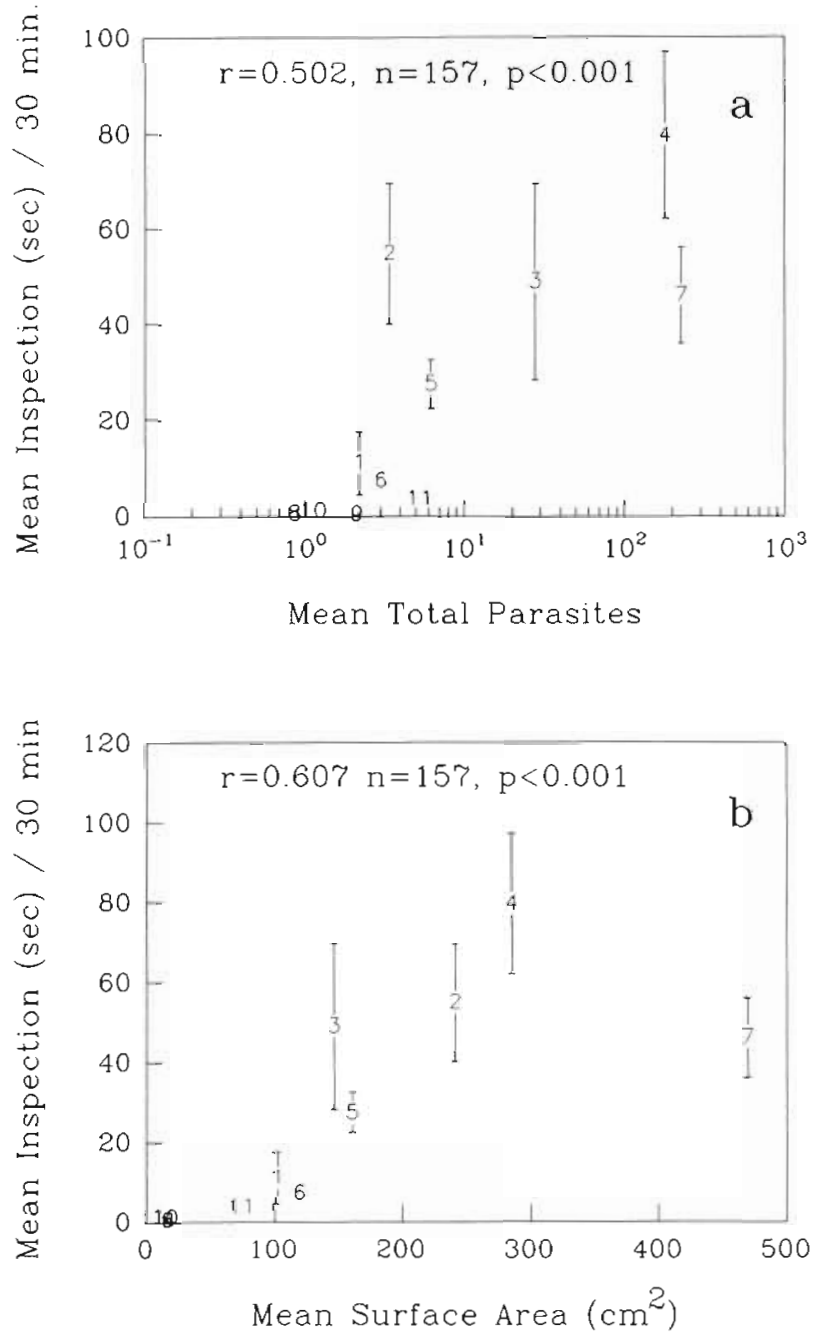

Fig. 3. The mean sum of the duration of inspections ( $\pm \mathrm{SE}$ ) by Labroides dimidiatus per 30 min observation period as a function of (a) mean number of parasites per fish species and (b) mean surface area per fish species. The duration of inspection was $\log _{10}(x+1)$-transformed while both parasites and surface area were $\log _{10}$-transformed to obtain linearity and homogeneity of variance for the correlation analyses. See

Fig. 1 for definitions of species

cies were cleaned about 144 times $d^{-1}$ (based on 12 daylight hours). In contrast, some smaller species with few parasites were inspected less than once per $30 \mathrm{~min}$ (Fig. 2). The duration of inspection for each fish species also increased with increasing parasite load (Fig. 3a) and increasing surface area (Fig. 3b). Siganus doliatus had the highest duration of inspection with about $80 \mathrm{~s}$ per $30 \mathrm{~min}$, which means individuals spend about

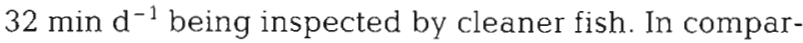
ison, small fish were often inspected for less than $1 \mathrm{~s}$ per $30 \mathrm{~min}$ (Fig. 3).

The frequency of inspection among species covaried with both parasite load and surface area (Table 1). In
Table 1. Analysis of covariance used to test for differences in the frequency of inspection among 11 fish species with mean surface area per fish species and mean total parasites per fish species as covariates. Tests of significance use Type l sequential sums of squares. Model 1: Frequency of inspection is first related to parasite load, the residual variation is then related to surface area, finally the remaining variation is examined for an effect of species. Model 2: Frequency of inspection is tested as above but with the order of the covariables reversed $\mathrm{CD}$ : coefficient of determination

\begin{tabular}{|lrrrrr|}
\hline Source & df & MS & $F$ & $\mathrm{p}$ & CD \\
\hline Model 1 & & & & & \\
Parasites & 1 & 3.795 & 42.72 & $<0.001$ & 0.185 \\
Area & 1 & 2.499 & 28.12 & $<0.001$ & 0.122 \\
Species & 8 & 0.151 & 1.69 & 0.104 & 0.059 \\
Model 2 & & & & & \\
Area & 1 & 5.997 & 67.50 & 0.001 & 0.293 \\
Parasites & 1 & 0.297 & 3.34 & 0.070 & 0.015 \\
Species & 8 & 0.151 & 1.69 & 0.104 & 0.059 \\
\hline
\end{tabular}

the first model of the ANCOVA, with the covariate parasite load introduced to the model first, parasite load was a significant covariate (Table 1, Model 1). However, surface area was still a significant covariate when it was adjusted for numbers of parasites (Table 1). The second model, which had the order of covariates reversed, shows area was a significant covariate (Table 1, Model 2). However, parasite load was no longer a significant covariable when adjusted for surface area (Table 1). The results of the first model and second model in Table 1 were not the same, which indicated that the covariables did not explain the variation equally. A comparison of the 2 models, using the $F$ and coefficient of determination values from each sequential analysis, show that surface area explained slightly more of the variation in the frequency of inspection (29.3\%) than did parasite load (18.5\%). This can also be seen in Fig. 2 which shows that the frequency of inspection has a higher correlation with surface area than with parasite load. Finally, the frequency of inspection was not significantly different among species when the effects of parasite load and surface area were removed (Table 1).

Parasite load and surface area were also significant covariates in the ANCOVA of the duration of inspection among species (Table 2, Models 1 and 2). The results of the first model and the second model were not the same, which indicated that the covariates did not explain the variation equally. Again, surface area appeared to explain slightly more of the variation in the duration of inspection (36.9\%) compared to parasite load (25.2\%). However, parasite load was still a significant covariate when adjusted for area but explained only $2.5 \%$ of the variation. Although the 
Table 2. Analysis of covariance used to test for differences in the duration of inspection among 11 fish species with mean surface area per fish species and mean total parasites per fish species as covariates. Tests of significance use Type I sequential sums of squares. Model 1: Duration of inspection. is first related to the parasite load, the residual variation is then related to the surface area, and finally the remaining variation is examined for an effect of species. Model 2: Duration of inspection is tested as above but with the order of the covariables reversed. CD: coefficient of determination

\begin{tabular}{|lrrrrr|}
\hline Source & df & MS & \multicolumn{1}{c}{$F$} & p & CD \\
\hline Model 1 & & & & & \\
Parasites & 1 & 23.597 & 67.21 & $<0.001$ & 0.252 \\
Area & 1 & 13.358 & 38.05 & $<0.001$ & 0.142 \\
Species & 8 & 0.698 & 1.99 & 0.052 & 0.007 \\
Model 2 & & & & & \\
Area & 1 & 34.593 & 98.53 & $<0.001$ & 0.369 \\
Parasites & 1 & 2.361 & 6.73 & 0.011 & 0.025 \\
Species & 8 & 0.698 & 1.99 & 0.052 & 0.007 \\
\hline
\end{tabular}

effect of species, when the effects of the covariates were removed, was nearly significant, it accounted for little of the total variation (Table 2, Models 1 and 2). These analyses are supported by Fig. 3, which shows that the duration of inspection has a higher correlation with surface area than with parasite load (Fig. 3).

Within a species, the number of times Hemigymnus melapterus was inspected by Labroides dimidiatus was significantly different among size classes (ANOVA, $\mathrm{MS}=0.683, \mathrm{df}=2,26, F=21.0, \mathrm{p}<0.001, \mathrm{CD}$ $=0.618$ ) (Fig. 4a). Larger fish were cleaned more often per 30 min than smaller fish, with the largest fish being cleaned about 5 times, medium sized fish about 4 times and small fish being cleaned less than once per 30 min (Fig. 4a). The duration of inspection per sample period was also significantly different among size classes (ANOVA, $\mathrm{MS}=3.426$, df $=2,26, F=35.69, \mathrm{p}<0.001$, $C D=0.733)$. On average, larger fish were cleaned for more time, with large fish being cleaned for about $45 \mathrm{~s}$ per sample period, medium sized fish for $30 \mathrm{~s}$, and small fish for $1 \mathrm{~s}$ (Fig. 4b).

\section{DISCUSSION}

Fish which were larger and had more parasites were inspected by cleaner fish more often than smaller fish which had less parasites. This pattern, determined by focal-animal sampling of the behavior of the host fish. occurred both between species and within a species. However, surface area, rather than parasite load, best explained the variation in cleaning rates among host species. This suggests that surface area may be useful for predicting host inspection rates. The link of host

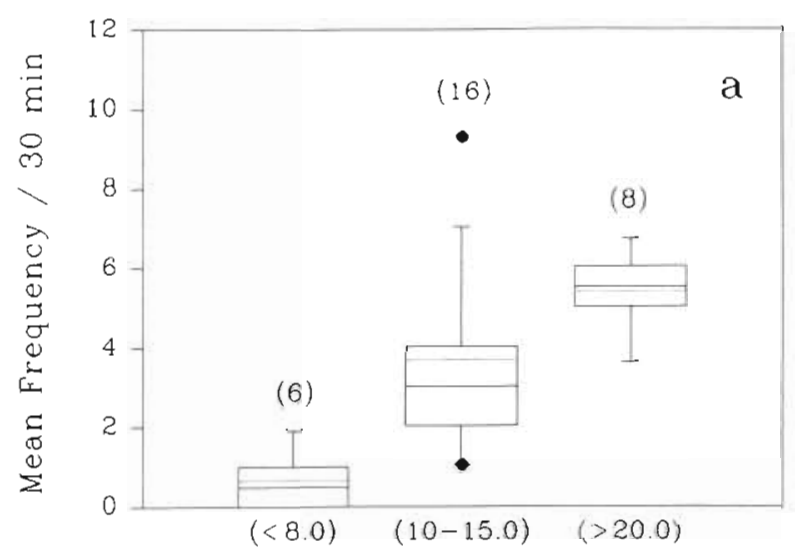

Fish Standard Length $(\mathrm{cm})$

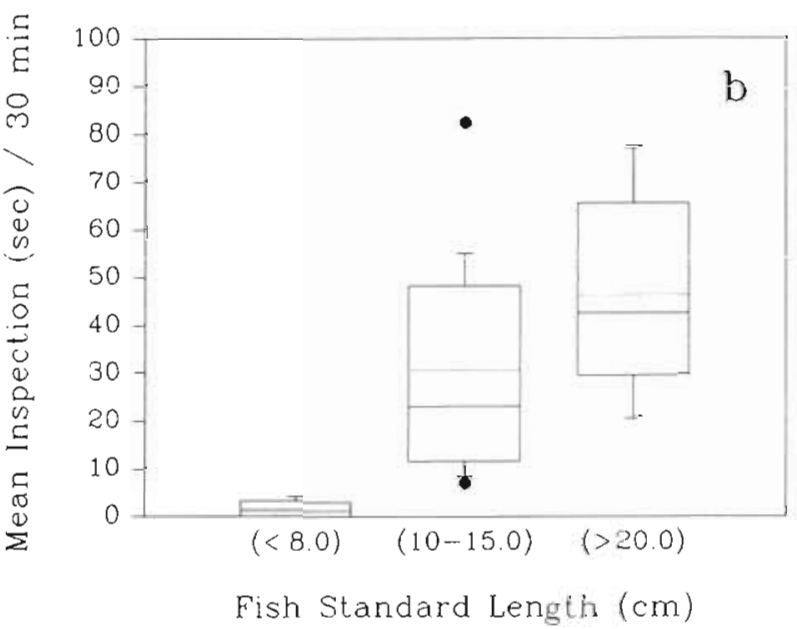

Fig. 4. Box plots of the inspections by Labroides dimidiatus of Hemigymnus melapterus from 3 size ranges. (a) Mean number of inspections per $30 \mathrm{~min}$ (sample size) (dotted line). (b) Mean sum of the duration of all inspections per $30 \mathrm{~min}$ observation (dotted line). Error bars indicate the upper 95\% quartile and lower $5 \%$ quartile, solid lines indicate median.

(•) Outlier

size with cleaning has been suggested already (Poulin 1993)

Because both the cleaner fish and host can determine the outcome of a cleaning bout (Losey 1971), the above patterns are probably a result of both cleaner fish feeding behavior and host cleaning behavior. If ectoparasite removal is the cause of the behavior for the host, one would expect parasite load to have a stronger effect on cleaning than host size. However because surface area is so important in the analyses described here, ectoparasite removal does not appear to be the primary cause of the behavior. It has been demonstrated that tactile stimuli have a large influence on the host's response towards cleaners (Losey 1979). Thus, fish with more surface area may cooperate more with cleaners because they receive more tactile stim- 
uli. Manipulation of parasite loads on fish and the subsequent effects on cleaning behavior are needed to examine whether parasite load influences host cleaning rates.

Cleaner fish can also influence cleaning rates by initiating and/or terminating an interaction (Losey 1979). If search time is a function of fish surface area, cleaner fish may influence the duration of inspection by spending more time on larger fish. How frequently host fish are cleaned may also be influenced by cleaner fish. Cleaner fish can reliably estimate the surface area of a fish from a distance but cannot estimate the parasite load of a fish until they have scanned the body for a few seconds. Because size and parasite load are so closely related (Noble et al. 1963, Cressey \& Collette 1971, Bortone et al. 1978, Buchmann 1989, Grutter 1994) and because cleaner fish also feed on the surface mucus of hosts (Gorlick 1980) and other surface materials (Randall 1958, Youngbluth 1968), cleaner fish may use size as an indicator of food availability. Parasites could therefore still drive the association but their proximate role would be somewhat masked by perceptual constraints acting on cleaners.

Surface area may be a better predictor of host cleaning rates simply because, within a species, surface may be less variable than parasite abundance. Within a species, parasite loads are variable (Grutter 1994). Therefore, the variation introduced into the study by using estimated mean parasite loads for each species, rather than using the parasite load of each fish observed, may have introduced error.

Once the effects of surface area and parasite load were removed, the differences in the inspection rates among species were not significant. This is surprising as some other host species display high levels of aggression during cleaning interactions, which may affect cleaner preference (Gorlick 1978, 1984). Some species also appear to seek cleaners more often while others often ignore cleaner fish. Fish species also have species-specific assemblages of parasites (Grutter 1994), which could influence cleaner fish feeding behavior. It is likely that fish size has a stronger effect on cleaning than species identity, thus species differences may be more apparent among similar sized species.

This study did not control for phylogenetic relationships among species which can introduce bias if closely related species share characteristics (e.g. size, parasite load) (Harvey \& Pagel 1991). Phylogenetic effects in the relationship between the tendency of hosts to seek cleaning (measured as the number of times fish species were observed with Labroides dimidiatus compared to the number of fish observed elsewhere) and the species' size (Poulin 1993) have been controlled using the independent comparisons method (Harvey \& Pagel 1991). A total of 5 of the 11 species in this study belong to the family Pomacentridae and are therefore more closely related to one another than the other 6 species. They are also all small and have few parasites. Thus the possibility arises that they were cleaned less than the other species because their lineage never developed a close association with cleaners. However, the relationship between cleaning and size and parasite load still appears to hold among these 5 species. Thus, if phylogeny is important, it may only influence the intensity of the relationship. Studies using phylogenetically independent contrasts of a range of species from a range of sizes are needed to resolve this issue

The cleaning rates obtained may be useful for measuring how many parasites cleaner fish remove from fish. Individuals of the species Siganus doliatus, for example, are cleaned about 144 times $d^{-1}$ and for $32 \mathrm{~min} \mathrm{~d}^{-1}$. This information, when combined with cleaner fish feeding behavior rates and parasite removal rates, can be used to estimate the number of parasites that a cleaner fish removes from a $S$. doliatus per day. A study measuring the parasite ingestion rate of cleaner fish has been completed and results will be reported elsewhere

Studies on factors influencing host cleaning behavior have suggested that parasite loads do not greatly affect cleaning behavior (Lasey 1971, 1979). However, this study shows that some species that do have many parasites spend a relatively large proportion of their waking hours being cleaned. Furthermore, both between and within species, fish with more parasites were cleaned more often and for a longer time. Finally, parasite load still explained some of the variation in the duration of inspection when adjusted for area. These findings all indicate that parasites and surface area play an important role in host cleaning.

Acknowledgements. I thank R. A. Alford, J. H. Choat, J. Caley, M. Milicich, H. Sweatman, and several anonymous reviewers for constructive comments on the manuscript. The Lizard Island Research Station Staff are gratefully acknowledged for their assistance as are $M$. Johnson, L. Linton and $F$. Grutter for their help in the field. I am indebted to G. De'ath and R. A. Alford who helped with the statistical analyses. This work was supported by an Australian Museum Post Graduate Grant and a Lizard Island Research Station Doctoral Fellow. ship. This is a contribution from the Lizard Island Research Station, a facility of the Australian Museum.

Addendum. In a recent taxonomic review of the family Scaridae, Scarus sordidus was renamed Chlorus sordidus (Bellwood 1994).

\section{LITERATURE CITED}

Altmann, J. (1974). Observational study of behavior: sampling methods. Behavior 49(3-4): 227-267 
Bellwood, D. R. (1994). A phylogenetic study of the parrotfishes family Scaridae (Picses: Labroidei), with a revision of genera. Rec. Aust. Mus. Suppl. 20: 1-86

Bortone, S. A., Bradley, W. K., Oglesby, J. L. (1978). The hostparasite relationship of two copepod species and two fish species. J. Fish Biol. 13: 337-350

Buchmann, K. (1989). Relationship between host size of Anguilla anguilla and infection level of the monogeneans Pseudodactylogyrus spp. J. Fish Biol. 35: 599-601

Cressey, R. F., Collette, B. B. (1971). Copepods and needlefishes: a study in host-parasite relationships. Fish. Bull. U.S. $68: 347-432$

Gorlick, D. L. (1978). Cleaning symbiosis: factors controlling host species preference and preference change in Labroides phthirophagus Randall. Ph.D. dissertation, University of Hawaii, Hilo

Gorlick, D. L. (1980). Ingestion of host fish surface mucus by the Hawaiian USA cleaning wrasse, Labroides phthirophagus, Labridae, and its effect on host species preference. Copeia 1980: 863-868

Gorlick, D. L. (1984). Preference for ectoparasite infected host fishes by the Hawaii UISA cleaning wrasse. Labroides phthirophagus, Labridae. Copeia 1984: 758-762

Gorlick, D. L., Atkins, P. D., Losey, G. S. (1978). Cleaning stations as water holes, garbage dumps, and sites of reciprocal altruism. Am. Nat. 112: 341-353

Grutter, A. S. (1994). Spatial and temporal variations of the ectoparasites of seven reef fish species from Lizard Island and Heron Island, Australia. Mar. Ecol. Prog. Ser. 115: $21-30$

Harvey, P. H., Pagel, M. D. (1991). The comparative method in evolutionary biology. Oxford University Press, Oxford

This article was presented by C. Birkeland, Mangilao, Guam
Hobson, E. S. (1971). Cleaning symbiosis among California inshore fishes. Fish. Bull. U.S. 69(3): 491-523

Losey, G. S. (1971). Communication between fishes in cleaning symbiosis. In: Cheng, T. C. (ed.) Aspects of the biology of symbiosis. University Park Press, Baltimore, p. 45-76

Losey, G. S. (1977). The validity of animal models: a test for cleaning symbiosis. Biol. Behav. 2: 223-238

Losey, G. S. (1979). Fish cleaning symbiosis: proximate causes of host behavior. Anim. Behav. 27:669-685

Losey, G. S. (1987). Cleaning symbiosis. Symbiosis 4: 229-258

Losey, G. S. (1993). Knowledge of proximate causes aids our understanding of function and evolutionary history. Mar. Behav. Physiol. 23: 175-186

Losey, G. S., Margules, L. (1974). Cleaning symbiosis provides a positive reinforcer for fish. Science 184: 179-180

Noble, E. R., King, R. E., Jacobs, B. L. (1963). Ecology of gill parasites of Gillichthys mirabilis, Ecology 44: 295-305

Okuno, R. (1969). Cleaning behaviors of the rainbow wrasse, Labroides dimidiatus. I. Jap. J. Ecol. 19(5): 184-191

Potts, G. W. (1973). The ethology of Labroides dimidiatus (Cuv. \& Val.) (Labridae. Pisces) on Aldabra. Anim. Behav. 21: $250-291$

Poulin, R. (1993). A cleaner perspective on cleaning symbiosis. Rev. Fish Biol. Fish. 3: 75-79

Randall, J. E. (1958). A review of the Labrid fish genus, Labroides, with descriptions of two new species and notes on ecology. Pacif. Sci. 12: 327-347

SAS (1991). SAS system for linear models, 3rd edn. SAS Institute Inc., Cary, NC

Youngbluth, M. J. (1968). Aspects of the ecology and ethology of the cleaning fish, Labroides phthirophagus Randall. Z. Tierpsychol. 25(8): 915-932

Manuscript first received: July 15, 1994

Revised version accepted: September 29, 1994 